\title{
Um Estranho à Minha Porta: Preparando Estudantes de Medicina para Visitas Domiciliares
}

\author{
A Stranger at My Door: Preparing Medical Students \\ for Home Visits
}

\author{
Ana Teresa de Abreu Ramos-Cerqueira ${ }^{I}$ \\ Albina Rodrigues Torres ${ }^{1}$ \\ Sueli Terezinha Ferreira Martins ${ }^{l}$ \\ Maria Cristina Pereira Limal
}

\section{PALAVRAS-CHAVE \\ - Educação médica. \\ - Visita domiciliar. \\ - Saúde mental. \\ - Psicodrama}

Recebido em: 16/01/2008

Reencaminhado em: 02/06/2008

Aprovado em: 09/06/2008

\section{RESUMO}

Este trabalho descreve a experiência de preparação de alunos do primeiro ano da Faculdade de Medicina de Botucatu-Unesp para as visitares domiciliares da disciplina Interação Universidade-Serviço-Comunidade. Docentes de Psicologia e Psiquiatria coordenaram a atividade, realizada com dois grupos de 45 alunos por meio da técnica de sociodrama, que inclui as etapas de aquecimento, dramatização e compartilhamento. Os principais temas trazidos pelos alunos nas dramatizações foram: a) briga e violência; $b$ ) miséria e carência; c) desapontamento e desinteresse; d) impotência e fracasso; e) rejeição e desconfiança. Assim, muitas situações temidas e emoções raramente abordadas nos cursos médicos puderam ser vivenciadas e elaboradas em poucas horas. Esta experiência reforça a necessidade de preparar o graduando para entrar em contato com os múltiplos e complexos determinantes do processo saúde-doença e para atuar no cuidado à saúde segundo uma perspectiva interdisciplinar e intersetorial. É fundamental que o aluno tenha uma visão ampliada do paciente inserido na sua família e contexto sociocultural, se dispondo a um trabalho de parceria, colaboração e mútuo aprendizado.

This study describes the experience in training first-year students at the Botucatu School of Medicine/ UNESP to conduct home visits as part of the course on University-Health Service-Community Interaction. Faculty members from the Departments of Psychology and Psychiatry coordinated the activity, with two groups of 45 students each, by means of the sociodrama technique, which includes warm-up, dramatization, and shared reflections. The main themes brought up by students in the dramatizations were: a) strife and violence; b) poverty and need; c) disappointment and disinterest; $d$ ) disempowerment and failure; and e) rejection and distrust. In just a few hours, it was thus possible to experience and elaborate on numerous potentially frightening situations and emotions that are rarely approached $d u-$ ring undergraduate medical training. This experience emphasizes the need to prepare undergraduates to make contact with multiple, complex determinants of the health-disease process and act in health care from an interdisciplinary and inter-sector perspective. It is essential for students to have an expanded view of patients within the family and socio-cultural context, drawing on partnership, collaboration, and mutual understanding. 


\section{INTRODUÇÃO}

Desde a sua criação, em 1963, a Faculdade de Medicina de Botucatu (FMB-Unesp) sempre teve por objetivo formar médicos generalistas, com visão crítica, reflexiva e contextualizada de sua prática profissional, buscando enfatizar na formação aspectos de ética, humanismo, cidadania, trabalho multiprofissional e atuação na comunidade.

Estes objetivos foram fortalecidos nos últimos anos, em função da aprovação das Diretrizes Nacionais Curriculares para os Cursos de Graduação em Medicina em novembro de $2001^{1}$, que apontam a necessidade de uma perspectiva de assistência integral à saúde, num sistema regionalizado e hierarquizado de referência e contrarreferência, e de atuação em equipe. Além disso, a FMB foi uma das escolas médicas brasileiras selecionadas para integrar o Programa de Incentivo às Mudanças Curriculares nos Cursos de Medicina (Promed) e o Pró-Saúde do Ministério da Saúde, em parceria com o Ministério da Educação, que visam exatamente incentivar a formação de profissionais aptos para atuar no Sistema Único de Saúde (SUS). Tais iniciativas pretendem evitar a fragmentação do ensino e a superespecialização precoce, assim como ampliar a visão do estudante da área de saúde sobre o complexo processo saúdedoença, buscando romper com o reducionismo biológico que conduz a separações entre determinantes psicológicos, sociais, culturais, ambientais e biológicos. Da mesma forma, buscam integrar ações de prevenção de doenças, promoção da saúde e ações curativas, assim como ações individuais e coletivas.

Desde 2003 vem sendo desenvolvida na FMB uma instigante experiência de ensino na comunidade, denominada "Interação Universidade, Serviço e Comunidade" (Iusc), na qual estudantes da primeira à terceira série do curso de Medicina desenvolvem atividades educativas na comunidade e em serviços de atenção básica, sempre em pequenos grupos supervisionados por professores tutores, profissionais das áreas de Biologia, Comunicação Social, Enfermagem, Fonoaudiologia, Medicina, Nutrição, Odontologia, Pedagogia, Psicologia, Serviço Social, Sociologia e Terapia Ocupacional, os quais contribuem com diferentes olhares e significados com o trabalho em equipe $^{2,3}$. O Iusc é um programa não departamental, ligado ao Núcleo de Apoio Pedagógico e sob a responsabilidade do Conselho de Curso de Graduação, aprovado em 2006 pela Congregação da FMB como disciplina oficial nos três primeiros anos do curso. A disciplina "centra seu foco na família inserida no universo das relações históricas, culturais, socioeconômicas e políticas da sociedade, procurando romper com a concepção biomédica no processo ensino-aprendizagem" ${ }^{\prime 3}$.

No primeiro ano do Iusc enfatiza-se o reconhecimento das condições de vida e saúde da população e o conhecimento dos dados demográficos e epidemiológicos da área onde o grupo de alunos atuará. Uma atividade proposta é acompanhar o desenvolvimento de crianças recém-nascidas, indicadas pela equipe da Unidade Básica de Saúde ou Unidade de Saúde da Família (UBS/USF), por meio de visitas domiciliares regulares, realizadas em duplas de alunos, para discutir aspectos de higiene, amamentação, nutrição e vacinação, entre outros.

Segundo Cyrino (p. 35) ${ }^{4}$, esta prática permite que o estudante

partindo de sua experiência de vida, de sua identidade cultural e da interação com os outros, possa tomar consciência do ambiente, da sociedade e do sistema produtivo, percebendo-se como cidadão coadjuvante do processo de transformação da realidade e como profissional comprometido com a saúde e a qualidade de vida de pessoas e comunidades.

Frente às angústias despertadas nos alunos com as atividades do Iusc, docentes das disciplinas de Psicologia e Psiquiatria da FMB foram convidados pelos coordenadores da disciplina em 2007 a colaborar na preparação dos alunos para as visitas domiciliares, com o objetivo de discutir expectativas, preocupações e sentimentos em relação a essa nova atividade. O presente artigo relata esta experiência, descrevendo a vivência proposta e as dificuldades e desafios identificados pelos estudantes do primeiro ano médico nas visitas domiciliares, atividade de introdução do ensino médico na comunidade.

\section{METODOLOGIA DA ATIVIDADE (VIVÊNCIA SOCIODRAMÁTICA)}

O procedimento escolhido para esse trabalho com os alunos foi o sociodrama, recurso técnico pertencente ao conjunto de estratégias utilizadas no psicodrama, que se aplica especialmente para trabalhar temas comuns aos grupos, sem focalizar aspectos individuais dos participantes. Esta técnica nasceu da necessidade de criar uma abordagem psicodramática cujo foco fosse fatores supraindividuais ou coletivos, pois, embora cada indivíduo viva num mundo que lhe parece privado e pessoal, esses mundos se sobrepõem em vários aspectos. Segundo Menegazzo et $a l^{5}$, o sociodrama possibilita trabalhar com grupos, identificando seus conflitos internos e fazendo com que, a partir de sua compreensão, estes possam ser resolvidos. Assim, o verdadeiro sujeito do sociodrama é o grupo, e não cada participante, não havendo espectadores e atores, mas sujeitos que participam como protagonistas da cena, por vasto que seja o grupo, como um "paciente coletivo" 6,7 .

Como recurso na formação de profissionais da saúde, em uma experiência com alunos de conclusão de curso de Medi- 
cina, o psicodrama auxiliou os estudantes na superação do estresse de final de curso e no levantamento de alternativas humanizadas em seu futuro exercício profissional ${ }^{8}$. Abdo ${ }^{9}$ relata a utilização desse recurso no ensino de Psicopatologia para alunos do quinto ano de Medicina, avaliando que o psicodrama estimula a aprendizagem e "permite o desenvolvimento de cursos mais dinâmicos, enriquecendo o papel do professor e propiciando ao aluno um interessante meio de aquisição de conhecimentos" (p. 116). Barreto e Santos ${ }^{10}$ utilizaram a técnica do role-playing com abordagem psicodramática na formação de médicos residentes, no desempenho do papel profissional, experiência que tem propiciado mudanças significativas na postura dos profissionais, em particular no relacionamento com outros membros da equipe de saúde. Na disciplina de Psicologia Médica da terceira série do curso de graduação em Medicina da FMB, a técnica de role-playing também vem sendo utilizada há muitos anos. No mesmo sentido, profissionais experimentaram os benefícios da técnica psicodramática em capacitação referente à humanização em saúde ${ }^{11,12}$.

\section{Participantes}

Noventa estudantes da primeira série do curso de graduação em Medicina da Faculdade de Medicina da Unesp, campus de Botucatu, divididos em dois grupos, cada um deles coordenado por dois docentes da área de saúde mental.

\section{Procedimentos}

O trabalho desenvolveu-se segundo as três fases clássicas do psicodrama: aquecimento, dramatização e compartilhamento (sharing). Um dos coordenadores elaborou um registro escrito após cada vivência, o qual foi lido pelos demais, acrescentandose observações consideradas relevantes. A análise da experiência foi discutida e elaborada conjuntamente pelos autores, a partir dos temas trazidos pelos alunos. É importante ressaltar que no psicodrama não se trabalha com hipóteses preconcebidas, mas são os conteúdos emergentes do grupo que direcionam a atividade, de modo espontâneo, apenas facilitado pelos coordenadores. Conforme assinalou Moreno ${ }^{6}$, o criador da técnica, cada sessão é única, original e irreproduzível, e nem os problemas nem seu percurso são previamente estabelecidos ou previstos.

\section{DESCRIÇÃO DA ATIVIDADE}

\section{Aquecimento inespecífico}

Iniciou-se pelo aquecimento inespecífico, necessário para possibilitar a ambientação, grupalização e preparação das pessoas para as cenas que dramatizarão em seguida ${ }^{13}$. A atividade de "aquecimento" dos grupos constou de uma autoapresentação breve e informal dos participantes, incluindo os diretores da atividade e professores tutores presentes.
Num dos grupos, os participantes foram orientados a se subdividir sucessivamente de acordo com características pessoais específicas (sexo, procedência da capital ou de cidades do interior do Estado, ou de outros Estados, maiores ou menores de 19 anos, com ou sem namorado(a), morando sozinho ou em república, etc.). Em meio a brincadeiras e risadas, observavam-se claramente inquietação e ansiedade diante da nova atividade, com professores tutores presentes e coordenadores desconhecidos.

No outro grupo, solicitou-se que cada um dos alunos se apresentasse rapidamente, nomeando apenas uma característica marcante de sua personalidade. Notou-se, inicialmente, resistência dos alunos de se envolverem na atividade de aquecimento, expressa em longos silêncios, lentidão para se levantarem das cadeiras, alegação de cansaço, o que demandou certo esforço dos coordenadores para dar continuidade à vivência.

\section{Aquecimento específico}

A seguir, solicitou-se aos alunos dos dois grupos que caminhassem lentamente pela sala, pensando em alguma situação que temessem enfrentar na visita domiciliar, por considerarem particularmente difícil de lidar. Caso houvesse várias situações temidas, deveriam, individualmente, selecionar aquela que lhes despertasse sentimentos mais fortes. A cena deveria, então, ser sintetizada e expressa numa única palavra ou frase curta, a ser dita ao restante do grupo. As palavras ditas foram anotadas no quadro-negro e agrupadas pelos temas comuns.

Os principais temas trazidos pelos alunos nos dois grupos foram: a) briga, violência, agressividade, conflito; b) miséria, carência, condições precárias de vida; c) quebra de expectativa, desinteresse, desapontamento; d) impotência, incompetência, fracasso, ansiedade; e) rejeição, falta de atenção, desconfiança, silêncio, impaciência.

Os alunos foram, então, subdivididos em grupos, de acordo com o tema de sua preocupação principal, e orientados a conversar entre si sobre as situações que imaginaram. Após algum tempo de trocas, sugeriu-se que elaborassem em conjunto uma cena dramática que representasse a essência da situação que cada subgrupo temia, escolhendo o cenário em que esta se daria, os personagens e as falas, ou até mesmo uma imagem estática reveladora da cena temida. A seguir, cada subgrupo apresentou suas cenas, em sequência livre. Estão relatadas as cenas comuns aos dois grupos.

\section{Dramatizações}

\section{CENA 1 (tema: impotência, incompetência, fracasso, ansiedade)}

Uma casa pobre na periferia da cidade. A mãe está muito ansiosa, pois seu bebê está febril, com muitas lesões de pele e ela não sabe o que fazer. Agradece a Deus porque as estudan- 
tes vieram e poderão ajudá-la. Constrangidas, as alunas dizem que são apenas alunas do primeiro ano e que vieram somente para conversar. A mãe se mostra decepcionada e diz: "Pra conversar não precisa, eu posso conversar com minha vizinha... Preciso é de ajuda com meu bebê..."

\section{CENA 2 (tema: miséria, carência, condições de vida muito precárias)}

Crianças famintas brincam na água suja e malcheirosa de um córrego, verdadeiro "esgoto a céu aberto". Dentro da casa, crianças se aglomeram num cômodo apertado e com goteiras. O bebê recém-nascido está magro, sujo, desnutrido, doente. A mãe explica: "A gente come o que dá, quando dá". Uma adolescente de 16 anos ajeita a barriga enorme de final da gravidez. As alunas tentam, sem sucesso, convencer a mãe de que deve tirar as crianças de perto do córrego imundo.

\section{CENA 3 (tema: quebra de expectativa, desinteresse, desapontamento)}

Mãe, avô e um bebê estão na casa. O bebê, que chora muito, está doente. A mãe diz que está tudo bem, pois já o levou na benzedeira e deu chá de romã. Os alunos se mostram impacientes e insistem com a mãe sobre a "conduta correta" e sobre os prejuízos de levar o bebê à "curandeira". Em tom ameaçador, dizem que, se a família não seguir as orientações, não vão voltar mais. A mãe se irrita com as críticas e os coloca para fora da casa, dizendo que eles só sabem "dar lição de moral", sem nem tentar entender o que acontece com eles.

\section{CENA 4 (tema: violência, agressividade, briga, conflito)}

Há muitas crianças na casa: o bebê, duas meninas brigando, um menino sapeca. A mãe atende a porta, dando "broncas" e "cascudos" nos filhos. Chega o pai, alcoolizado e extremamente agressivo, ofendendo e expulsando os alunos, que ficam paralisados de medo, raiva e impotência. As coordenadoras convidam a classe a tentar ajudar, um aluno entra em cena, se aproxima do pai, cumprimenta-o estendendo a mão, se apresenta e explica a razão da visita. Volta todo o seu foco de atenção para este homem, que se acalma um pouco e o aceita novamente dentro da casa.

\section{CENA 5 (tema: rejeição, falta de atenção, desconfiança, silêncio, impaciência)}

Numa casa do bairro estão: um avô "surdo", uma mulher calada e de rosto pouco expressivo e um pai saindo apressado para o trabalho, dizendo que não tem tempo pra conversar com os alunos. Mal deixa que eles comecem a falar e, impa- ciente, já os coloca para fora, dizendo que sente muito, mas que está atrasado, que aquilo é perda de tempo. Diz que eles não tiveram "estudo", mas que sempre se viraram sem aquelas visitas, que desenvolvimento de criança é coisa natural, que não precisa dessa "frescura" de acompanhamento dos estudantes da faculdade.

\section{Compartilhamento (sharing)}

Convidados a falar sobre seus sentimentos, os alunos dos dois grupos destacaram principalmente a impotência e a frustração que experimentaram ao se imaginarem diante dessas famílias. Impotência por não saberem "ainda" o que fazer com o bebê febril ou com diarréia: "Ah, se estivéssemos no sexto ano...". Impotência porque não têm como resolver problemas estruturais do País, como a pobreza extrema que acreditam que irão encontrar em todas as casas. Impotência porque não há como mudar a cultura, ou a "falta de cultura/ignorância" da mãe que deixa os filhos brincarem no córrego sujo, que leva o filho para benzer e lhe dá chá de romã. Impotência e ansiedade diante da situação crônica de abuso e violência em que vivem algumas famílias. Frustração por não serem bem recebidos, como na cena 5. Assim, impotência, sensação de fracasso e frustração, ansiedade, medo, pena, tristeza e raiva foram os sentimentos predominantes nos dois grupos.

Questionados sobre como se sentiram durante e após vivenciarem as cenas, todos os que se manifestaram disseram estar se sentindo diferentes, modificados. Muitos afirmaram que estavam mais tranquilos e aliviados. Um aluno, no entanto, afirmou que estava mais preocupado, pois antes não havia pensado em tantas possibilidades de problemas. Alguns disseram que conseguiram "sentir" melhor todas as dificuldades dessas famílias, que não se resolvem com ações simples, isoladas ou pontuais. Os professores tutores do Iusc presentes se manifestaram surpresos pela riqueza do material trazido espontaneamente pelos alunos, destacando a grande quantidade de situações e emoções que puderam ser vivenciadas e elaboradas em tão curto espaço de tempo.

\section{DISCUSSÃO}

É interessante destacar as semelhanças entre as cenas dramatizadas pelos alunos dos dois grupos, centradas nos temas da insegurança, do medo do desconhecido e do próprio desconhecimento, na expectativa de miséria, ignorância, rejeição e mesmo agressividade contra eles. Isso denota que, no imaginário dos alunos, há de fato temas e sentimentos comuns, que puderam ser explicitados e discutidos pelo método sociodramático, em que os grupos foram protagonistas. Além disso, apesar de temas diferentes, as cenas tinham muitos aspectos de sobreposição. 
Alguns pontos centrais podem ser destacados a partir das cenas e do compartilhamento das mesmas. Observou-se que: 1) a expectativa dos alunos de atuação como médicos é centrada no papel curativo, no binômio diagnosticar/tratar, havendo muito medo de errar, de não saber como agir, de não terem respostas, principalmente por se considerarem "representantes" da instituição; 2) há uma expectativa de grande dificuldade de comunicação com as famílias em função da diferença de condições socioeconômicas e culturais, diferença que funcionaria como uma barreira, impossibilitando qualquer escuta e entendimento entre eles e a população; 3) os estudantes tendem a desvalorizar e a considerar como indicadores de ignorância conceitos, crenças e valores que estão em desacordo com os seus próprios; 4) há grande sentimento de impotência diante das enormes necessidades sociais da população, agudizado pela visão de que as soluções estão centradas em um único profissional, desconhecendo-se a possibilidade da atuação interdisciplinar e intersetorial como mediadora de cuidado à saúde; 5) há insegurança de que terão retaguarda adequada para a atuação nas visitas domiciliares; 6) o aluno tem dificuldade de compreender seu papel como membro da equipe de saúde e possível facilitador do vínculo da família com a Unidade Básica de Saúde sem ser um invasor, mas, sim, um parceiro e colaborador; 7) há tendência de se considerar, preconceituosamente, pobreza como sinônimo de ignorância, sujeira, famílias numerosas e desorganizadas/conturbadas, desemprego, alcoolismo, migração (houve sotaque nordestino em algumas cenas), hostilidade e violência; e 8) há dificuldade de pensarem que, pelo contrário, podem ser bem recebidos e tratados com respeito e consideração pelas famílias, que podem estabelecer uma rica relação de troca de conhecimentos e experiências diferentes, e que o vínculo e a confiança devem se estabelecer gradualmente, durante as sucessivas visitas. Ou seja, a ansiedade dos alunos impede que percebam a visita às famílias como um processo que está apenas se iniciando, mas como algo que deve ter começo, meio e fim numa primeira e única visita, que tem que ser resolutiva e sem falhas.

Como as cenas foram dirigidas para situações temidas imaginárias, era esperado que somente as dificuldades fossem trazidas pelos alunos, mas todos esses pontos puderam ser discutidos com eles e com os professores tutores no final do compartilhamento, gerando grande alívio da ansiedade grupal.

\section{Implicações para o ensino médico}

Esta vivência sociodramática de preparação para as visitas domiciliares expõe a necessidade de preparar o graduando de Medicina para entrar em contato com toda a complexidade dos múltiplos determinantes do processo saúde-doença e da pers- pectiva interdisciplinar e intersetorial do cuidado à saúde. Nesse sentido, fica claramente demonstrado que aspectos sociais, culturais e educacionais são indissociáveis das questões de "doença" e que é fundamental aprender desde o início do curso habilidades de comunicação e de trabalho em equipe multiprofissional.

Além disso, é importante que consigam contextualizar adequadamente os problemas de saúde e condutas de acordo com as condições gerais de vida dos pacientes, oferecendo possibilidades de escuta ampliada e promovendo encontros. Destaca-se também a importância de os alunos entrarem em contato com os sentimentos que são despertados na relação com pacientes e familiares, para poderem compartilhá-los e elaborá-los em contexto adequado e em conjunto com seus pares, já que são bastante semelhantes. Sabe-se que durante o curso médico o estudante sofre grande carga emocional, principalmente pelo contato com o sofrimento alheio, mas que em geral nos currículos tradicionais tais experiências afetivas raramente são adequadamente abordadas ${ }^{14,15}$. Na verdade, alguns estudos em nosso meio vêm apontando altas taxas de sofrimento emocional entre alunos de Medicina ${ }^{16,17,18}$.

Outro aspecto essencial do ensino na comunidade é a mudança de paradigma, não mais apenas da doença para a saúde, mas de prevenção de doenças e promoção da saúde, considerando o sujeito inserido em sua família e contexto sociocultural, num trabalho de parceria, colaboração e mútuo aprendizado, e não de simples assistencialismo. Esta parece ser uma contribuição fundamental do Iusc da FMB-Unesp, que vai ao encontro das novas Diretrizes Curriculares do Ensino Médico ${ }^{1}$, visando formar médicos generalistas com uma compreensão ampliada de seu objeto de prática, não mais centrado apenas no indivíduo biológico. As atividades de ensino realizadas extramuros também podem gerar mais oportunidades de reflexão crítica e de questionamento da prática profissional, assim como do exercício responsável da cidadania.

\section{Elaboração da vivência ou a metavivência: "estranhos à porta dos alunos"}

É interessante perceber que os estudantes reproduziram conosco, durante a vivência, as suas próprias cenas temidas, invertendo os papéis. Como coordenadoras da vivência, éramos pessoas igualmente estranhas e desconhecidas, que chegavam à "casa/classe" desses alunos para "invadir" sua privacidade. De fato, nós, profissionais de saúde mental da instituição, não integramos o corpo docente do curso do Iusc no primeiro ano e quase nada sabíamos do programa do curso. Assim, estávamos, como os primeiranistas frente ao bebê com febre ou diarréia, inseguras por não saber o que encontraríamos, como seríamos recebidas e se saberíamos o que fazer nessa situação 
tão nova para todos. Deste modo, não é surpreendente que tenhamos sido recebidas no início da atividade com ansiedade, resistência e mesmo hostilidade pelos alunos. Ressalte-se que, enquanto um dos subgrupos preparava a cena de violência, uma de nós foi convidada a participar dela: "Precisamos de alguém para apanhar", alegaram, brincando.

Inevitável também é lembrar que estes estudantes, primeiranistas do curso, são eles próprios "recém-nascidos", recémchegados à Faculdade de Medicina, tentando se inserir numa "família" nova dentro da instituição, precisando de ajuda e apoio para vivenciar sua própria experiência de construção gradual e contínua do papel profissional, que envolve importante dimensão de natureza afetiva, frequentemente ignorada nas grades curriculares.

\section{AGRADECIMENTO}

A Miguel Perez Navarro, que, como nosso supervisor durante muitos anos, nos ensinou toda a riqueza da técnica psicodramática e seu potencial de despertar a criatividade e a espontaneidade das pessoas, assim como de aproximá-las e transformá-las.

\section{REFERÊNCIAS}

1. Brasil. Ministério da Educação. Resolução CNE/CES no 4. Institui Diretrizes Curriculares Nacionais do Curso de Graduação em Medicina. 7 nov. 2001.

2. Cyrino EG, Martins STF, Prearo AY, Manoel CM, Oikawa LT. O programa: história, princípios e estratégias. In: Cyrino EG et al (Org.). A universidade na comunidade. Educação médica em transformação. Botucatu: Cyrino (Editor); UNESP; 2005. p.21-31.

3. Cyrino EG et al. Em busca da recomposição da arte do cuidado e do fazer/aprender: a interação universidade, serviço, comunidade na Faculdade de Medicina de Botucatu/ Unesp. In: Pinheiro R, Ceccim RB, Mattos RA. (Org.). Ensino - trabalho - cidadania: novas marcas ao ensinar integralidade no SUS. Rio de Janeiro: IMS/UERJ; 2006. p.71-84.

4. Cyrino EG. Humanizar é preciso: a dimensão essencial do cuidado. In: Cyrino EG. et al (Org.). A universidade na comunidade. Educação médica em transformação. Botucatu: Cyrino (Editor), UNESP; 2005. p.33-39.

5. Menegazzo CM, Tomazini MA, Zuretti MM. Dicionário de Psicodrama e Sociodrama. São Paulo: Agora; 1995. 232p.

6. Moreno JL. Psicoterapia de grupo e psicodrama. Introdução à teoria e à práxis. São Paulo: Mestre Jou; 1974.

7. Moreno JL. Psicodrama. São Paulo: Cultrix; 1975.

8. Ramos-Cerqueira ATA, Lima MCP, Torres AR, Reis JRT, Fonseca NMV. Era uma vez... contos de fada e psicodrama auxiliando alunos na conclusão do curso médico. Interface Comum saúde Educ. 2005; 9 (16): 81-90.
9. Abdo CHN. Ensino de psicopatologia nas instituições. In: Ricotta LCA (Org.). Psicodrama nas instituições. São Paulo: Agora; 1990. p.113-117. (Cadernos de Psicodrama, 1)

10. Barreto SLD, Santos MBL. Role-playing na instituição. In: Ricotta LCA (Org.). Psicodrama nas instituições. São Paulo: Agora; 1990. p.135-137. (Cadernos de Psicodrama, 1)

11. Pamplona V, Baptista MCV. O psicodrama na promoção da humanização na assistência à saúde. Rev Bras Psicodrama. 2004;12(1):45-52.

12. Ribeiro SFR, Martins STF. Oficina de teatro espontâneo com trabalhadores do Programa de Saúde da Família: um espaço de expressão e reflexão. Pesquisas e Práticas Psicossociais. 2007; 1: 221-228.

13. Davoli C. Aquecimento: caminhos para dramatização. Rev bras psicodrama. 1997;5(1):51-61.

14. Ramos-Cerqueira ATA, Lima MC. A formação da identidade médica: implicações para o ensino de graduação em Medicina. Interface comun saúde educ. 2002;6(11):107-116.

15. Peres CM, Andrade AS. Atividades extracurriculares: representações e vivências durante a formação medica. [Acesso em 24 nov. 2007]. Disponível em: http:/ / stoa.usp. br/antandras/files/318/1474/Repres_alun_univ_ativ_ extracurr.pdf

16. Moro A, Valle JB, Lima LP. Sintomas depressivos nos estudantes de medicina da Universidade da Região de Joinville (SC). Rev Bras Educ Med. 2005; 29(2): 97-102.

17. Souza FGM, Menezes Neto GC. Estresse nos estudantes de Medicina da Universidade Federal do Ceará. Rev Bras Educ Med 29(2):91-96.

18. Lima MCP, Domingues MS, Cerqueira ATAR. Prevalência e fatores de risco para transtornos mentais comuns entre estudantes de medicina. Rev saude Publica. 2006;40:1035-1041.

\section{CONTRIBUIÇÃO DOS AUTORES}

Todas as autoras coordenaram as vivências sociodramáticas realizadas com os estudantes de Medicina, contribuindo igualmente na organização do relato de experiência, da revisão da literatura e da redação do artigo.

\section{CONFLITO DE INTERESSES}

Declarou não haver

\section{ENDEREÇO PARA CORRESPONDÊNCIA}

Departamento de Psicologia

Faculdade de Medicina de Botucatu - UNESP

Distrito de Rubião Jr. - Botucatu

CEP.:18618-970 - SP

E-mail: ateresa@fmb.unesp.br 